\title{
Simulation as an educational strategy to deliver interprofessional education
}

\author{
R van Wyk, ${ }^{1}$ MHPE, BComm (IT); M J Labuschagne, ${ }^{1}$ MB ChB, MMed (Ophth), PhD (HPE); G Joubert, ${ }^{2}$ BA, MSc
}

${ }^{1}$ Clinical Simulation and Skills Unit, Faculty of Health Sciences, University of the Free State, Bloemfontein, South Africa

${ }^{2}$ Department of Biostatistics, Faculty of Health Sciences, University of the Free State, Bloemfontein, South Africa

Corresponding author: $R$ van Wyk (vanwykr3@ufs.ac.za)

\begin{abstract}
Background. Various educational methods are available to deliver interprofessional education (IPE) to prepare healthcare students for collaborative practice. One such method is simulation-based health education.

Objectives. To identify current IPE methods used in undergraduate programmes in the Faculty of Health Sciences at the University of the Free State, Bloemfontein, South Africa, and to determine the opinions of module leaders on using simulation as a particular IPE teaching strategy.

Methods. A quantitative, cross-sectional descriptive study design was employed. Structured interviews were conducted with 47 module leaders of the undergraduate programmes in the Faculty of Health Sciences. These programmes cover 66 modules in the Schools for Allied Health Professions (nutrition and dietetics, occupational therapy, physiotherapy and optometry), nursing and medicine.

Results. At the time of the study, IPE activities were used in 29 (43.9\%) of the modules, of which 17 (58.6\%) were coincidental. Respondents' opinions on the potential use of simulation to address formalised IPE activities included the challenge of 'scheduling' (73.9\%) and 'logistical and high cost issues' (19.6\%). The most prominent advantage that was foreseen (41.3\%) was better clarification of roles among the different professions.

Conclusions. The module leaders had a positive attitude towards simulation and its potential use for IPE, with their major concern being logistical challenges. To improve role clarification, a scenario should be developed to engage students from all the relevant professions. The proposed type of simulation was to use standardised patients in a role-play scenario. The outcomes of these activities should be aligned with the principles of IPE.
\end{abstract}

Afr J Health Professions Educ 2020;12(2):74-80. https://doi.org/10.7196/AJHPE.2020.v12i2.1213

Evolving developments in healthcare and patient populations result in patients with more complex needs, which highlights the need for interprofessional patient-centred collaborative care. It is apparent that no single profession can respond adequately in isolation to such complex needs. ${ }^{[1]}$ The lack of interprofessional collaboration and communication has been cited as a contributing factor in up to 98000 preventable deaths per year in the USA. ${ }^{[2]}$ Other negative consequences with regard to inadequate interprofessional communication are delays in patient care, poor patient outcomes and wasted staff time and resources. ${ }^{[2]}$ Although no similar data could be found for South Africa (SA), it could be assumed that ineffective communication and teamwork that lead to adverse patient events might be even worse in SA owing to the 11 official languages. Members of a healthcare team might have difficulty in expressing themselves in a particular language. ${ }^{[3]}$ Interprofessional education (IPE) is very often advised as a corrective measure in such cases. ${ }^{[4]}$

The fragmented SA healthcare systems in the private and public sectors could be strengthened by the inclusion of IPE to improve health outcomes. This will align with the World Health Organization (WHO)'s framework for action on IPE and collaborative practice that will enable the future healthcare workforce to apply collaborative practice effectively. ${ }^{[5]}$ IPE could contribute to the way SA healthcare professionals are trained to become agents of change to address the health needs of the SA population. ${ }^{[6,7]}$

To prepare healthcare students for collaborative practice, various educational methods could be used to deliver IPE. One approach that has been suggested comprises three elements, i.e. didactic learning experiences, simulation-based experiences and community-based IPE learning experiences. $^{[8]}$

Didactic learning experience is most effective when it takes the form of interprofessional, small-group guided discussions on the concepts of interprofessional practice. ${ }^{[9]}$ Simulation-based health education can be defined as a training and feedback method where learners practise tasks and processes in lifelike circumstances using models or virtual reality, with feedback from observers, peers, simulated patients and video cameras to assist improvement of skills. ${ }^{[10]}$

According to Botma et al. ${ }^{[11]}$ the main purpose of interprofessional simulation is an increase in patient safety. It also serves as an education strategy to break down professional barriers. Interprofessional simulation sessions have their own unique challenges, such as logistical issues, strain on resources and managing teams with learners from different foundational backgrounds. ${ }^{[12]}$ Scott et al. ${ }^{[13]}$ identified clinical outcomes for the interprofessional team and also competencies such as communication, teamwork and professionalism. IPE simulation scenarios should be developed with these specific competencies listed as learning objectives.

Effective simulation experiences depend on the availability of experts to develop scenarios with interprofessional outcomes in mind, ${ }^{[13]}$ as well as facilitators for effective debriefing and reflection. ${ }^{[3]}$ Baker et al. ${ }^{[12]}$ stated that learners find simulation-based interprofessional experiences useful and relevant. Community-based learning experiences depend on groups of students from multiple professions working in a setting, such as a clinic in a rural area with a selected community partner. ${ }^{[8]}$ 
In all three of these elements, the clinical outcomes of the interprofessional team should be accompanied by profession-specific competencies, common competencies and IPE competencies. IPE competencies include collaboration, communication, teamwork and professionalism. Exposure of students to these elements serves to break down barriers between professions and contributes to clarifying the different roles of each profession in the interprofessional team.

The IPE programme of the Faculty of Health Sciences (consisting of the Schools of Medicine, Nursing and Allied Health Professions, the latter comprising the Departments of Nutrition and Dietetics, Occupational Therapy, Physiotherapy and Optometry) of the University of the Free State (UFS) ${ }^{[9]}$ which was initiated in 2014, incorporated common competencies, profession-specific competencies and interprofessional competencies. These competencies are depicted in Fig. 1.

After an initial pilot phase, four 2-hour IPE sessions have been presented to all fourth-year health science students from six professions since 2015. The first session provides a theoretical background of and orientation on IPE. The second and third are simulated sessions with a standardised patient and a facilitator (lecturers from various professions) for each group. The simulation takes the form of a hospital setting with the standardised patient playing the role of a stroke patient. The group manages the patient as an interprofessional team, focusing on collaborative practice and interprofessional competencies. After each session, a facilitator debriefs the students. Each debriefing session is divided into two parts - the first includes the standardised patient, who gives feedback to the group from a patient's perspective. The second part of the debriefing excludes the standardised patient. During the fourth session, the groups present an interprofessional care plan for collaborative practice that could be applied to community-based rotations later in their fourth year. ${ }^{[1]}$

The intention of these sessions is to improve students' conceptual grasp of collaborative practice (principles of collaboration, professionalism, communication and improving healthcare systems) ${ }^{[9]}$ and to prepare them for community-based interprofessional rotations.

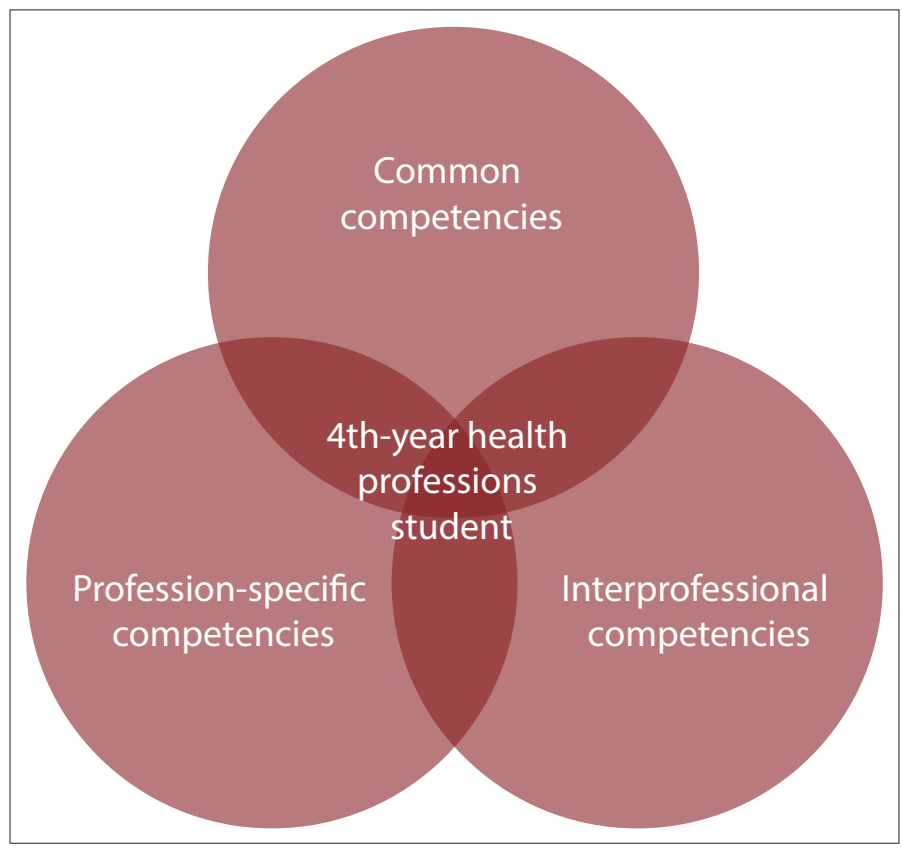

Fig. 1. Elements of interprofessional education in health professions programmes.

\section{Objective}

The aim of the study was to determine the opinions of the module leaders in the undergraduate programmes in the Faculty of Health Sciences, UFS, on using simulation as a learning strategy in IPE.

\section{Methods \\ Design}

A quantitative, cross-sectional descriptive study design was employed. To provide the necessary context, the current approach of undergraduate module leaders across all three schools in the Faculty of Health Sciences with regard to IPE, was determined as part of the study.

\section{Sampling and participants}

Participants were module leaders in the undergraduate programmes of the School for Allied Health Professions (consisting of the Departments of Nutrition and Dietetics, Occupational Therapy, Physiotherapy and Optometry), School of Nursing and School of Medicine at UFS. A participant could be the module leader of more than one module.

\section{Data collection}

Structured interviews were conducted by the first author (RvW).

The structured interview was divided into four main sections. Firstly, demographic data of the module leader were obtained. The second section ascertained whether any IPE activity took place within the module(s) and, if so, in which form. The third section obtained the module leader's opinion on aspects of simulation-based medical education. In this section, various statements about simulation-based health education were given and participants had to use a 5-point Likert scale to indicate their responses. The last section obtained the module leader's opinion on the possible use of simulation to address IPE needs. Principles and characteristics of health simulation as described by $\mathrm{Ziv}^{[14]}$ were used as a guide in the formulation of questions/statements and options of the interview schedule.

\section{Pilot study}

A pilot study was conducted with three of the module leaders, one from each school. These module leaders were selected by simple random sampling from each school, using random.org. After the first pilot interview, a minor adjustment was made to the interview schedule (the question options on formal v. informal IPE were changed to allow the option for both formal and informal). The data from all three pilot interviews were included in the main study.

\section{Data analysis}

All quantitative data were coded and summarised on an Excel version 14.0 (Microsoft, USA) spreadsheet by the first author to ensure confidentiality before it was sent to the Department of Biostatistics, UFS, for analysis. Results were summarised by frequencies and percentages. Answers to open-ended questions were noted in writing during the interview. These answers were then coded into themes by the first author and summarised quantitatively. In the presentation of the results, it was indicated whether the denominator consisted of module leaders or modules.

\section{Ethical approval}

Approval for the study was obtained from the Ethics Committee of the Faculty of Health Sciences, UFS (ref. no. ECUFS 146/2014). Permission to 
conduct the research was granted by the heads of the three schools involved, the dean of the Faculty of Health Sciences and the UFS vice-rector: research.

\section{Results}

Fifty-seven module leaders representing 80 modules were approached to participate in the study. Interviews were conducted with 47 module leaders (response rate of $82.5 \%$ ) who covered 66 modules (representing $82.5 \%$ of the total number of modules). Some module leaders represented more than one module. The School of Medicine (16 of 19 disciplines) had a total of 58 modules (46 (79.3\%) were represented), the School of Nursing 4 of 4 (100\%) and the School for Allied Health Professions 16 of 18 (88.9\%).

The median number of years of experience of teaching undergraduate health professions students was 12 (range 1 - 43), which was also the median for their number of years of teaching at UFS.

The academic years of students represented in the modules ranged from 1 to 5 in the School of Medicine, and from 1 to 4 in the School for Allied Health Professions and the School of Nursing. The distribution of the modules across the academic years of the undergraduate programmes is shown in Table 1.

Considering the opinions of module leaders on simulation (Table 2), the majority $(n=38 ; 80.8 \%)$ indicated that simulation should not completely replace bedside training on real patients (clinical work); however, the

Table 1. Distribution of modules covered by interviews $(n=66)$ across the undergraduate programmes presented in the Faculty of Health Sciences, University of the Free State

\begin{tabular}{ll}
\hline Academic year & $\boldsymbol{n}(\%)$ \\
\hline 1st year* & $15(22.7)$ \\
2nd year* & $15(22.7)$ \\
3rd year* & $19(28.8)$ \\
4th year* & $12(18.2)$ \\
5th year $\dagger$ & $5(7.6)$ \\
& \\
& *Schools for Allied Health Professions, Nursing and Medicine. \\
&
\end{tabular}

majority ( $n=39 ; 83.0 \%)$ indicated that some clinical work could be replaced by simulation sessions. The majority $(n=44 ; 93.7 \%)$ of module leaders indicated that simulation sessions could replace some of the traditional classes.

More than half of the module leaders were of the opinion that simulation sessions (in general) were not disruptive to the schedule. However, many of them $(n=29 ; 61.7 \%)$ indicated that they needed more time in the schedule to add simulation sessions. With the exception of one module leader, the majority $(n=46 ; 97.9 \%)$ indicated that simulation sessions and the use of debriefing/reflection increased the students' understanding of a problem.

Most of the module leaders indicated that simulation was a safe environment for students ( $n=46 ; 97.9 \%)$ and patients $(n=45 ; 95.7 \%)$. More than two-thirds $(n=32 ; 68.1 \%)$ said that simulation would be beneficial to their module(s) and enhance clinical training, and that small-group learning $(n=40 ; 85.1 \%)$ would be an effective strategy to employ in their module(s). More than $90 \%$ of module leaders were of the opinion that simulation could be used for training of technical and non-technical (professional attributes) skills.

The percentage of modules per year during which students are exposed to some form of IPE, is shown in Table 3. The largest percentages are during the latter years of the undergraduate programme. In the second year of study, students are only exposed to some form of IPE in 2 of the 15 modules, i.e. $13.3 \%$ of second-year modules.

In the 29 modules (43.9\%) where IPE has been incorporated, 17 (58.6\%) coincidentally used IPE activities. In 7 (24.1\%) of the 29 modules, formal IPE activities were used, while in $5(17.2 \%)$ of these modules a combination of formal and coincidental IPE activities was employed. Formal activities included those where IPE outcomes were assessed, while informal activities were considered as coincidental without outcome measures and assessment. The percentages of IPE activities in the 29 modules are shown in Table 4. With regard to time, IPE comprised $\leq 10 \%$ in more than half $(58.6 \%)$ of these modules.

Table 2. Module leaders' $(n=47)$ opinions on simulation-based health education

\begin{tabular}{|c|c|c|c|c|c|}
\hline & 1 & 2 & 3 & 4 & 5 \\
\hline Statement & $\begin{array}{l}\text { Strongly } \\
\text { disagree, } n(\%)\end{array}$ & $\begin{array}{l}\text { Disagree, } \\
n(\%)\end{array}$ & $\begin{array}{l}\text { No opinion, } \\
n(\%)\end{array}$ & $\begin{array}{l}\text { Agree, } \\
n(\%)\end{array}$ & $\begin{array}{l}\text { Strongly } \\
\text { agree, } n(\%)\end{array}$ \\
\hline All traditional lessons can be substituted by simulation sessions & $13(27.7)$ & $22(46.8)$ & $4(8.5)$ & $7(14.9)$ & $1(2.1)$ \\
\hline Some traditional lessons can be substituted by simulation sessions & $0(0)$ & $2(4.3)$ & $1(2.1)$ & $20(42.6)$ & $24(51.1)$ \\
\hline There is enough time in the schedule to add simulation sessions & $11(23.4)$ & $18(38.3)$ & $2(4.3)$ & $12(25.5)$ & $4(8.5)$ \\
\hline A simulation learning environment is safe for students & $0(0)$ & $0(0)$ & $1(2.1)$ & $6(12.8)$ & $40(85.1)$ \\
\hline A simulation learning environment is safe for patients & $0(0)$ & $1(2.1)$ & $1(2.1)$ & $12(25.5)$ & $33(70.2)$ \\
\hline Simulation can be used for assessment & $1(2.1)$ & $1(2.1)$ & $0(0)$ & $17(36.2)$ & $28(59.6)$ \\
\hline Simulation sessions are non-disruptive to the schedule & $5(10.6)$ & $5(10.6)$ & $8(17.0)$ & $17(36.2)$ & $12(25.5)$ \\
\hline Small-group training is effective for the module & $1(2.1)$ & $4(8.5)$ & $2(4.3)$ & $8(17.0)$ & $32(68.1)$ \\
\hline Reflection/debriefing enhances students' understanding & $0(0)$ & $1(2.1)$ & $0(0)$ & $9(19.1)$ & $37(78.7)$ \\
\hline Simulation is a 'nice to have' and cannot be used for module outcomes & $24(51.1)$ & $8(17.0)$ & $2(4.3)$ & $5(10.6)$ & $8(17.0)$ \\
\hline Simulation can be used for non-technical skills & $1(2.1)$ & $0(0)$ & $1(2.1)$ & $15(31.9)$ & $30(63.8)$ \\
\hline Simulation can be used for science/technical skills & $0(0)$ & $0(0)$ & $1(2.1)$ & $12(25.5)$ & $34(72.3)$ \\
\hline Simulation may lead to deeper understanding of a problem & $0(0)$ & $1(2.1)$ & $0(0)$ & $10(21.3)$ & $36(76.6)$ \\
\hline Simulation training can replace all practical, real patient management & $23(48.9)$ & $15(31.9)$ & $3(6.4)$ & $6(12.8)$ & $0(0)$ \\
\hline Simulation training can replace some practical, real patient management & $1(2.1)$ & $5(10.6)$ & $2(4.3)$ & $24(51.1)$ & $15(31.9)$ \\
\hline Staff are aware of advantages of simulation training & $3(6.4)$ & $7(14.9)$ & $10(21.3)$ & $18(38.3)$ & $9(19.1)$ \\
\hline Staff are aware of disadvantages of simulation training & $2(4.3)$ & $8(17.0)$ & $10(21.3)$ & $18(38.3)$ & $9(19.1)$ \\
\hline
\end{tabular}


The types of IPE activities used in the 29 modules are summarised in Fig. 2, with some modules using more than one type of IPE activity. In 19 (65.5\%) of the modules, ward rounds were used to deliver IPE, although the amount of IPE-specific exposure during such rounds was not determined.

Respondents representing 44 (66.7\%) of the 66 modules indicated that they did not consider simulation as a viable learning strategy to address IPE in that specific module. The main reason was that no IPE activities

Table 3. Modules that include IPE exposure per academic year

\begin{tabular}{ll}
\hline Academic year & Modules with IPE, $\boldsymbol{n}$ (\%) \\
\hline 1st year, $n=15$ & $5(33.3)$ \\
2nd year, $n=15$ & $2(13.3)$ \\
3rd year, $n=19$ & $11(57.9)$ \\
4th and 5th year, $n=17$ & $11(64.7)$ \\
IPE = interprofessional education. &
\end{tabular}

\section{Table 4. Modules that include IPE $(n=29)$}

\begin{tabular}{ll}
\hline IPE, \% & $\boldsymbol{n}(\%)$ \\
\hline $0-10$ & $17(58.6)$ \\
$11-20$ & $5(17.2)$ \\
$21-30$ & $4(13.8)$ \\
$31-40$ & $1(3.4)$ \\
$41-50$ & $2(6.9)$ \\
$51-100$ & $0(0)$
\end{tabular}

IPE $=$ interprofessional education

Table 5. Reasons for not considering simulation as a viable training tool in modules not incorporating IPE $(n=44)$

\begin{tabular}{ll}
\hline Reasons & $\boldsymbol{n}(\%)$ \\
\hline No IPE activities in the module & $37(84.1)$ \\
IPE is informal and coincidental & $6(13.6)$ \\
Paper cases and group work are adequate & $4(9.0)$ \\
Concept of own profession not yet formed & $3(6.8)$ \\
Only multiprofessional classes & $2(4.5)$ \\
IPE = interprofessional education. &
\end{tabular}

were employed in the module; also, IPE could be regarded as informal and coincidental (Table 5). In some cases, more than one reason was given.

In the $22(33.3 \%)$ modules where simulation could be considered a viable learning strategy, the types of simulation were mainly role-play $(n=17$; $77.3 \%$ ), followed by standardised patients ( $n=14 ; 63.6 \%$ ) (Fig. 3).

With regard to foreseen disadvantages of using simulation in IPE, 10 of $46(21.3 \%)$ interviewees mentioned that they did not foresee any disadvantages. As shown in Table 6, the potential disadvantages most commonly mentioned were the high costs of simulation and logistical challenges $(n=9 / 46 ; 19.6 \%)$.

The two main advantages identified by module leaders for using simulation to address IPE were that it would improve role clarification among students of the different professions $(n=19 / 46 ; 41.3 \%)$ and that it would be a safe learning environment for students and patients $(n=15 / 46$; $32.6 \%$ ) (Table 6).

Approximately three-quarters of respondents $(n=34 / 46 ; 73.9 \%)$ indicated that scheduling was the main challenge when considering simulation for IPE, while $10(21.7 \%)$ were concerned about the attitude of the staff and that a paradigm shift would be needed (Table 7).

\section{Discussion}

In this study, the focus was on simulation as a mode of delivery in IPE. Most of the module leaders interviewed were of the opinion that simulation could be a useful strategy to train students in the practice of interprofessional collaborative care. One of the main advantages identified was the improvement of role clarification among professions in a safe learning environment where real patients were not used. Simulated scenarios could improve interprofessional teamwork, empathy and respect for other professions.

When developing IPE simulation scenarios, students from all the relevant professions should be engaged. The proposed types of simulation could be standardised patients in a role-play scenario, hybrid simulation or high-fidelity team-training simulation. ${ }^{[13]}$ In this study, role-play and simulated patients were considered as the most effective types of simulation. Virtual reality simulation was considered by $<10 \%$ of participants. The limited exposure of the module leaders to virtual reality simulation at this institution could explain the response.

Table 6. Disadvantages and advantages of using simulation for IPE in health education $(n=46)$

\begin{tabular}{|c|c|c|c|}
\hline Disadvantages & $n(\%)$ & Advantages & $n(\%)$ \\
\hline Logistical issues and high costs & $9(19.6)$ & Improves role clarification among the different professions & $19(41.3)$ \\
\hline Negative attitudes or unprepared students & $8(17.4)$ & Safe learning environment for students and no real patients are used & $15(32.6)$ \\
\hline Balance between the focus on multiple professions & $5(10.9)$ & Improves empathy and respect for other professions & $9(19.6)$ \\
\hline Too artificial & $4(8.7)$ & Improves students' training through expanded platform and scenarios & $9(19.6)$ \\
\hline Shallow interactions/not enough critical reasoning & $4(8.7)$ & Improves students' training through exposure to other professions & $9(19.6)$ \\
\hline Conflict within a group leads to negative perceptions & $3(6.5)$ & Improves teamwork among professions & $8(17.4)$ \\
\hline Cannot replace real patients completely & $2(4.3)$ & Improves professional and inter-team communication & $6(13.0)$ \\
\hline Students might feel exposed among other professions & $2(4.3)$ & Improves patient management & $4(8.7)$ \\
\hline Theory might not be learnt & $1(2.2)$ & Opportunity for students to reflect & $3(6.5)$ \\
\hline Could lead to compartmentalising of skills & $1(2.2)$ & Better preparation for real-world situations and clinical training & $3(6.5)$ \\
\hline Own role/profession must first be defined & $1(2.2)$ & Improves students' non-technical skills & $3(6.5)$ \\
\hline 'Hidden roles' difficult to expose with simulation & $1(2.2)$ & Assessment could be objective and ongoing & $2(4.3)$ \\
\hline Undergraduate students not exposed to simulation & $1(2.2)$ & Fewer staff might be needed for simulation than for $\mathrm{CBE}$ & $1(2.2)$ \\
\hline
\end{tabular}




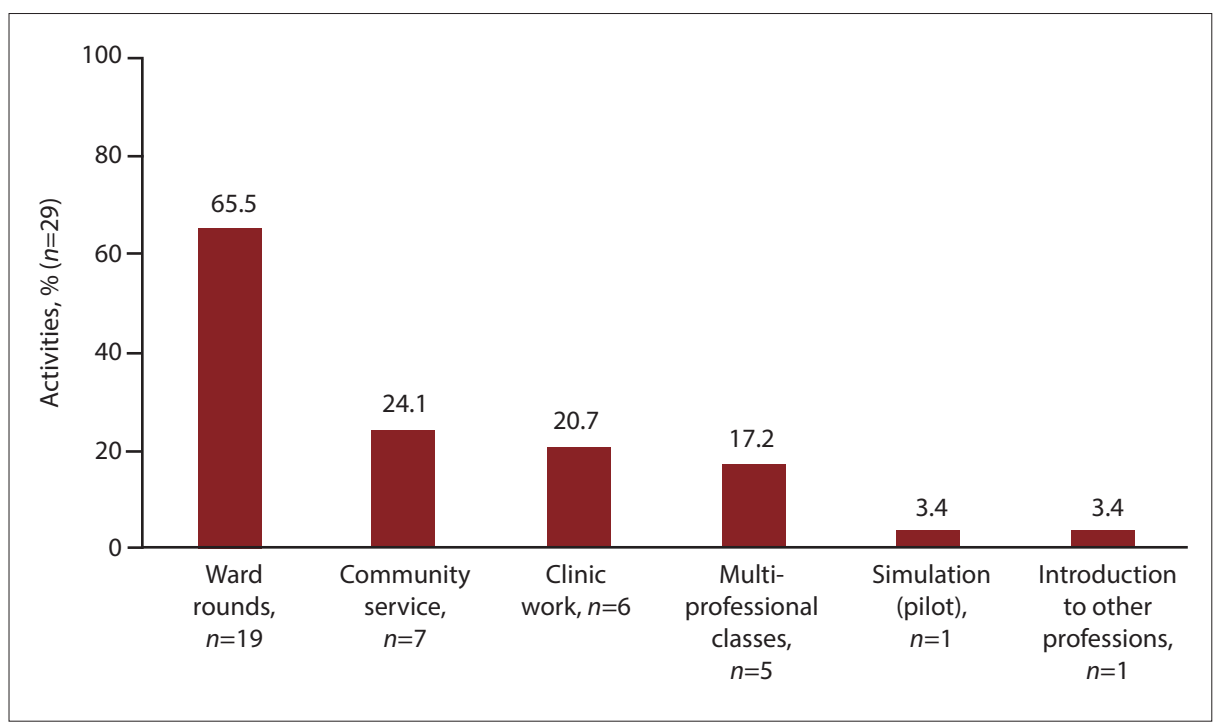

Fig. 2. Different types of interprofessional education activities $(\mathrm{n}=29)$.

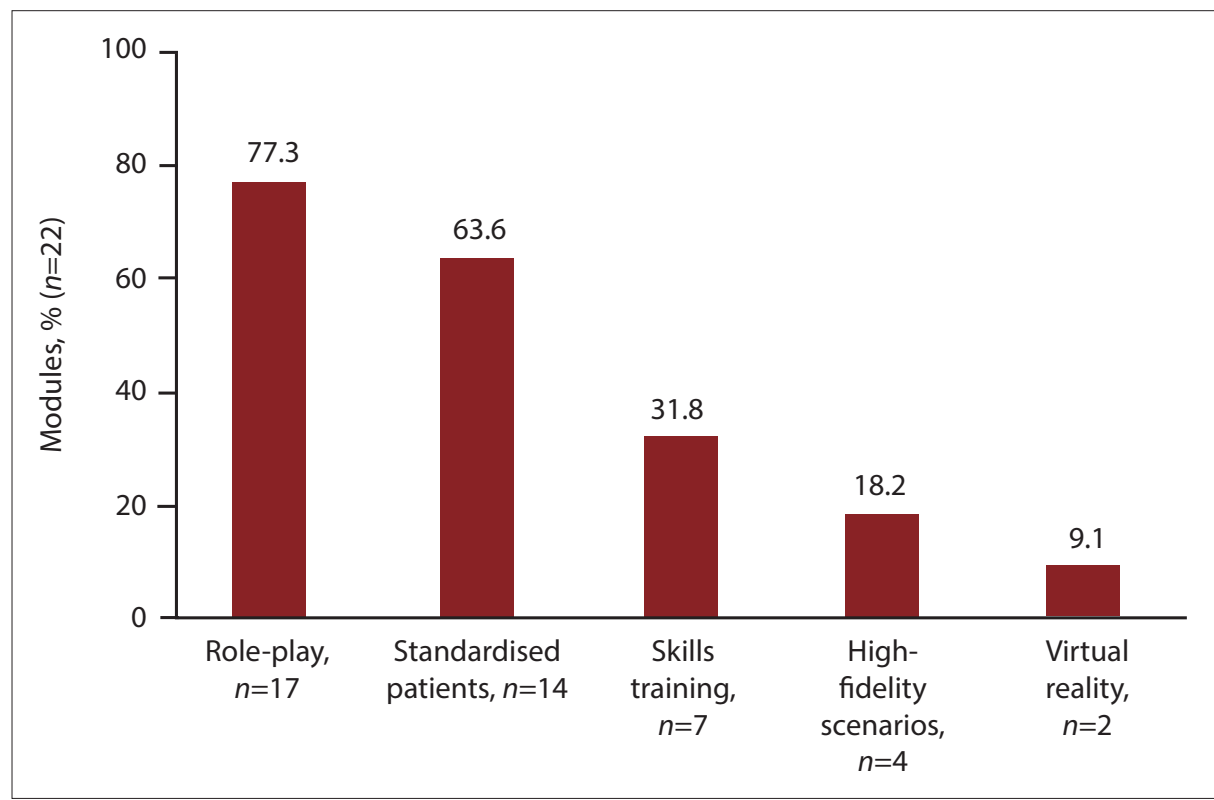

Fig. 3. Type of simulation considered for interprofessional education in modules where it was regarded as viable $(\mathrm{n}=22)$.

The outcomes should also specifically be aligned with the principles of IPE. Learning opportunities must be carefully aligned with students' interests, concerns and level of expertise. $^{[15]}$ This is more challenging with IPE, as there might be great diversity among multidisciplinary students. ${ }^{[16]}$ Simulation provides a safe learning environment for students, which was mentioned by 15 (31.9\%) of the participants in this study. The other advantages of simulation as a mode of delivery for IPE were identified as improved role clarification, empathy and respect for other professions and patients, improved learning collaborative practice. ${ }^{[19]}$ IPE should be part of the institutional culture. ${ }^{[20]}$ Educational methods to deliver IPE, such as didactic learning experiences, community-based learning experiences and simulation experiences, can be employed. ${ }^{[8]}$

Interprofessional simulation sessions have unique challenges, such as:

- Logistical issues, e.g. the challenge to schedule an interprofessional group of students from different professions, departments and rosters. Baker et al. ${ }^{[12]}$ argued that logistical challenges were some of the major concerns when implementing IPE into a curriculum, a matter that was echoed by the participants in this study.

- Resource-intensive challenges, e.g. multiple simulation venues are often needed for sessions. Because of the small groups comprising each session, multiple sessions are needed. Strain is also placed on staff (of different professions) with regard to their availability as facilitators and to provide technical support. ${ }^{[12]}$ In our study, high costs were a concern mentioned by $\sim 20 \%$ of participants.

- For effective interprofessional simulation, members of staff need to be trained as facilitators in the principles of IPE and simulation methodology. ${ }^{[21]}$ All facilitators receive intensive training in IPE before the sessions at our institution.

- According to Baker et al., ${ }^{[12]}$ students with varied foundational backgrounds may require orientation sessions prior to simulation to clarify technical and IPE concepts.

- Negativity and bad role modelling might have a negative influence on the attitude of students regarding IPE. ${ }^{[12]}$ In this study, potential disadvantages of using simulation for IPE included negative attitudes and unprepared students.

- Organisations might not be structured effectively for the high level of collaboration needed between different professions for effective interprofessional simulation. ${ }^{[21]}$

- A culture of non-collaboration would initially need to be addressed in some cases. ${ }^{[21]}$

skills, healthcare professionals must also equipped with a broader set of non-technical skills. ${ }^{[17]}$ Healthcare workers can virtually never work in isolation; therefore, collaboration, communication and professionalism are paramount to successful teamwork and patient care. $^{[18]}$ Interprofessional collaborative care does not occur coincidentally; students must deliberately be exposed to IPE, which can promote these skills and develop a healthcare student into an effective team member in a
Keeping the advantages and disadvantages of IPE simulation in mind, care should be taken to balance the workload of students to prevent overloading and prompting surface learning. ${ }^{[2]}$ Students' level of prior learning and establishment of a personal professional identity are necessary for successful IPE, and will leverage their existing knowledge to enhance their learning opportunities. ${ }^{[23]}$ 


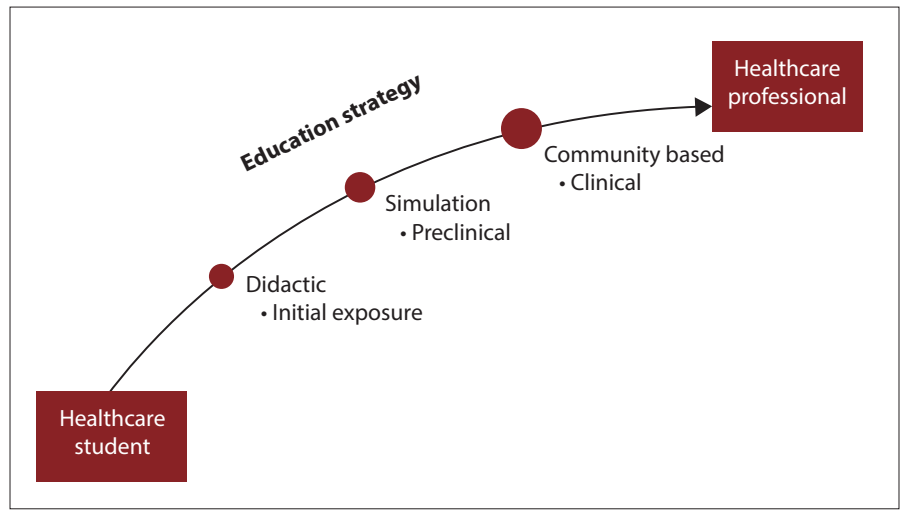

Fig. 4. Proposed learning continuum for interprofessional education, and the platforms used.

Table 7. Potential challenges of using simulation for IPE in health education $(n=46)$

\begin{tabular}{ll}
\hline Potential challenges & $\boldsymbol{n}(\%)$ \\
\hline Scheduling challenges & $34(73.9)$ \\
Paradigm shift needed from staff & $10(21.7)$ \\
Staff resources & $9(19.6)$ \\
Physical resources and correct equipment & $8(17.4)$ \\
Difficult to standardise training for multiple professions & $8(17.4)$ \\
Simulation needs to be more realistic & $4(8.7)$ \\
Potential negative attitudes from students & $4(8.7)$ \\
Challenging to apply formal assessment of IPE & $1(2.2)$
\end{tabular}

IPE $=$ interprofessional education

Successful simulation education has to challenge students, but these challenges should be monitored and adjusted to ensure productive learning. Initially, the facilitator should structure the programme, but as students' confidence increases, these structured approaches may be reduced. ${ }^{[24]}$ Repeated, deliberate practice leads to improved performance, and opportunities for regular practice in IPE should be incorporated into training programmes. ${ }^{[25]}$

As with most other skills, repeated practice is vital to embed interprofessional collaboration skills longitudinally into a curriculum. Reflection and feedback can lead students to self-evaluate, seeking constant improvement and exploring alternative strategies to a problem. The most effective feedback for IPE is guided, structured feedback (debriefing after simulation), ${ }^{[26]}$ and facilitators should be trained in the debriefing of interprofessional groups. Debriefing could be the most difficult part of simulation, but this is where learning occurs. ${ }^{[27]}$ The main purpose of interdisciplinary simulation and debriefing is to increase patients' safety. It also serves as an education strategy to break down professional barriers. ${ }^{[11]}$

To enhance IPE in the undergraduate programmes at our institution, we propose a three-phase longitudinal approach. These three phases are in line with the elements proposed by Bridges et al. ${ }^{[8]}$ and include the use of didactic lessons at initial exposure level, simulated interprofessional experiences at the preclinical level and a community-based education platform during the clinical level (Fig. 4). During all three levels, IPE and collaborative practice principles and values should be addressed (Fig. 1). This approach would expose students to IPE principles at all levels during their studies. This form of exposure would ensure structured, guided and non-coincidental IPE and transference to the workplace. Each phase of training should incorporate an assessment component.

When the adapted version of Miller's framework for clinical assessment ${ }^{[28]}$ is considered, this three-phase longitudinal approach addresses all the relevant levels of training. The didactic lessons (initial exposure phase) ensure that students have the relevant knowledge about IPE ('knows'). The simulation experiences (preclinical) ensure students are competent in the 'knows how' and 'shows how' aspects of IPE. The community-based interprofessional aspect (clinical) would build on the first two levels and ensure that students are able to 'show how' and 'do'. Consequently, all the building blocks are in place for students to develop their sense of professionalism ('is').

\section{Study limitations}

Limitations identified in the study were that interviews were conducted only with module leaders and not all lecturers involved in the presentation of these modules, and the approach to assessment of IPE activities was not explored during the interviews. The understanding of terms such as simulation and IPE was not determined. Since the conception of the IPE simulation project in 2013, IPE and simulation have been discussed and addressed with various role-players, including the faculty's module leaders, on various platforms such as strategic planning meetings.

\section{Conclusions}

Although there are various challenges, using simulation to enhance IPE is a viable and realistic approach in a number of modules in undergraduate training at our faculty. During simulation debriefing sessions, deliberate emphasis on patient-centred collaborative practice can enhance the principles in students' minds, enabling them to bridge the gap between theory and practice. This would lead to transference of collaborative practice principles, and improved, more effective, patientcentred management and care. The three-tiered longitudinal approach can help students to experience the principles of collaborative practice and may lead to improvement of a fragmented healthcare system to the advantage of patients and professions.

\section{Declaration. None.}

Acknowledgements. The module leaders who participated in the study; and Dr Daleen Struwig, medical writer/editor, Faculty of Health Sciences, University of the Free State, for technical and editorial preparation of the manuscript.

Author contributions. RvW and MJL conceptualised the study, GJ provided methodological input. RvW collected the data and GJ analysed the data. RvW drafted the manuscript, which all authors reviewed and edited.

Funding. None.

Conflicts of interest. None.

1. Barr H. Interprofessional education. In: Dent JA, Harden RM, eds. A Practical Guide for Medical Teachers. 3rd ed. Edinburgh: Churchill Livingstone, 2009:187-192.

. Olenick M, Allen LR. Faculty intent to engage in interprofessional education. J Multidiscip Healthcare 2013;6:149-161. https://doi.org/10.2147/JMDH.S38499

3. Botma Y, Butler M, Coetzee D, Hattingh R, Labuschagne M, van Wyk R. Interprofessional Education, Faculty of Health Sciences. Bloemfontein: University of the Free State, 2014

Kohn LT, Corrigan JM, Donaldson MS. To Err is Human. Building a Safer Health System. Washington, DC National Academy Press, 2000

World Health Organization. Framework for Action on Interprofessional Education and Collaborative Practice. Geneva: WHO, 2010.

6. Van Heerden B. Effectively addressing the health needs of South Africa's population: The role of the health professions education in the 21st century. S Afr Med J 2012;103(1):21-22. https://doi.org/10.7196/SAMI.6463 
7. Frantz JM, Rhoda AJ. Implementing interprofessional education and practice: Lessons from a resource-constrained universily. Jhterprof Care 2017;31(2):180-183. https://doi.org/10.1080/13561820.2016.1261097

8. Bridges DR, Davidson RA, Odegard PS, Maki IV, Tomkowiak J. Interprofessional collaboration: Three best practice models of interprofessional education. Med Educ Online 2011;16(1):6035. https://doi.org/10.3402/meo.v16i0.6035 9. Botma Y, Labuschagne M. Student's perceptions of interprofessional education and collaborative practice: Analysi of freehand drawings. I Interprof Care 2019;33(3):321-327. https://doi.org/10.1080/13561820.2019.1605981

10. Eder-van Hook J. Building a National Agenda for Simulation-based Education. Washington, DC: Advance Initiatives in Medical Simulation, 2004.

11. Botma Y, Brysiewics P, Chipps J, Mthembu S, Phillips M. Creating Stimulating Learning Opportunities. Cape Town: Pearson, 2014.

2. Baker C, Pulling C, McGraw R, Dagnone JD, Hopkins-Rosseel D, Medves J. Simulation in interprofessiona education for patient-centred collaborative care. J Adv Nurs 2008;64(4):372-379. https://doi.org/10.1111/j.13652648.2008.04798.x

13. Scott HM, Perrone J, Drozd A. Dimensions in paediatric simulation: Teamwork and communication. In: Gallo K Smith LG, eds. Building a Culture of Patient Safety through Simulation. An Interprofessional Learning Model. New York: Springer, 2015:127-142

4. Ziv A. Simulators and simulation-based medical education. In: Dent JA, Harden RM, eds. A Practical Guide for Medical Teachers. 3rd ed. Edinburgh: Churchill Livingstone, 2009:217-222.

Knowles MS, Holton EF, Swanson RA. The Adult Learner: The Definitive Classic in Adult Education and Human Resource Development. 8th ed. New York: Routledge, 2015.

16. Freeth D. Interprofessional education. In: Swanwick T, ed. Understanding Medical Education: Evidence, Theory and Practice. Edinburgh: Association for the Study of Medical Education and Wiley-Blackwell, 2007:53-68.

17. Thistlethwaite JE. Interprofessional education. In: Dent JA, Harden RM, eds. A Practical Guide for Medical Teachers. 4th ed. Edinburgh: Churchill Livingstone, 2013:190-198.

18. Chan AK, Wood V. Preparing tomorrow's healthcare providers for interprofessional collaborative patient-centred practice today. UBC Med J 2010;1(2):22-24
19. Haire B. Interprofessional Care: A Model of Collaborative Practice. Prince Edward Island. PEI Health Sector Counsel, 2010

0. Casimiro L, MacDonald CJ, Thompson TL, Stodel EJ. Grounding theories of W(e)Learn: A framework for onlin interprofessional education. J Interprof Care 2009;23(4):390-400. https://doi.org/10.1080/13561820902744098 21. Robertson J, Bandali K. Bridging the gap: Enhancing interprofessional education using simulation. J Interpro Care 2008;22(5):499-508. https://doi.org/10.1080/13561820802303656

22. Ruiz-Gallardo J, Castano S, Gomez-Alday JJ, Valdes A. Assessing student workload in problem based learning. Relationships among teaching method, student workload and achievement. A case study in natural sciences. Teach Teacher Educ 2011;27(3):619-627. https://doi.org/10.1016/j.tate.2010.11.001

23. Freeth DS, Hammick M, Reeves S, Koppel X, Barr H. Effective Interprofessional Education: Development Delivery and Evaluation. Oxford: Blackwell Publishing, 2005.

4. Barr H, Koppel I, Reeves S, Hammick M, Freeth D. Effective Interprofessional Education: Argument, Assumptio and Evidence. Oxford: Blackwell Publishing, 2005.

25. Ericsson K, Krampe R, Tesch-Römer C. The role of deliberate practice in the acquisition of expert performance. Psychol Rev 1993;100(3):363-406. https://doi.org/10.1037/0033-295X.100.3.363

26. Clark PG. Reflecting on reflection in interprofessional education: Implications for theory and practice. Interpro Care 2009;23(3):213-223. https://doi.org/10.1080/13561820902877195

27. Østergaard D, Dieckmann P. Simulation-based medical education. In: Dent JA, Harden RM, eds. A Practical Guide for Medical Teachers. 4th ed. Edinburgh: Churchill Livingstone, 2013:207-214.

28. Cruess RL, Cruess SR, Steinert Y. Amending Miller's pyramid to include professional identity formation Acad Med 2016;91(2):180-185. https://doi.org/10.1097/ACM.0000000000000913

Accepted 14 October 2019 